\title{
A experiência de mundo de uma surda ao aprender LIBRAS: uma abordagem fenomenológico-existencial
}

\section{The world experience of a deaf learning LIBRAS: An existential-phenomenological approach}

\section{La experiencia en el mundo de una sorda a aprender LIBRAS: Un enfoque fenomenológico-existencial}

\author{
Amanda Galerani Thomaz \\ Universidade Federal do Paraná - UFPR, Curitiba, Paraná, Brasil \\ Joanneliese de Lucas Freitas \\ Universidade Federal do Paraná - UFPR, Curitiba, Paraná, Brasil
}

\begin{abstract}
RESUMO
Frequentemente os diferentes discursos sobre a experiência da surdez partem da perspectiva dos ouvintes, tornando opaca essa vivência tão particular. Esse trabalho pretendeu se aproximar da experiência de se viver no mundo cultural sem a apropriação de uma língua sistematizada. Para tanto, foi realizado um estudo de caso sobre uma surda que aprendeu a Língua Brasileira de Sinais (LIBRAS) já adulta. A coleta de dados deu-se por meio de uma entrevista aberta, mediada por um intérprete voluntário de LIBRAS. A análise da entrevista foi orientada pelo método fenomenológico de investigação de Giorgi e os dados interpretados a partir da perspectiva de Merleau-Ponty. Os resultados foram divididos em dois grupos temáticos: $O$ mundo sem sentido: vazio e solidão e $O$ despertar aos sentidos: "uma nova vida". As vivências anteriores ao domínio de uma língua sistematizada foram descritas como incompreensíveis e vazias, permeadas por dissociações e experiências esparsas. Ao aprender LIBRAS, a entrevistada relata uma mudança brusca na forma como se relacionava com o mundo, começando a perceber sentidos e gestos compartilhados culturalmente. Sugere-se estudos mais aprofundados que investiguem o sensível e a corporeidade na experiência das pessoas surdas. Destaca-se a importância da apropriação da língua sistematizada.
\end{abstract}

Palavras-chave: surdez, fenomenologia-existencial, linguagem, sentido, Merleau-Ponty.

\begin{abstract}
Different discourses on the experience of deafness frequently start from the perspective of the listeners, which implies an opacity of this very particular experience. This work aims to approximate the experience of living in the cultural world without the appropriation of a systematic language. Thus, was conducted a case study of a deaf who learned the Brazilian Sign Language (LIBRAS) as an adult. Data collection took place through an open interview, mediated by a LIBRAS's volunteer interpreter. The interview analysis was
\end{abstract}


guided by Giorgi's phenomenological method of research and the data interpreted from the perspective of Merleau-Ponty. The results were divided into two thematic groups: The meaningless world: emptiness and loneliness and Awakening the senses, "a new life". The experiences lived before mastering a systematic language were described as incomprehensible and empty, permeated by dissociation and sparse experiences. The interviewed reported a sudden change in how she was connected to the world after she had learned LIBRAS, when she begun to realize culture's shared meanings and gestures. It is suggested further studies that investigate the sensible and corporeal experience of deaf people. It highlights the importance of apprenticeship of a systematic language.

Keywords: deafness, existential-phenomenology, language, meaning, Merleau-Ponty.

\begin{abstract}
RESUMEN
A menudo, los diferentes discursos sobre la experiencia de la sordera emergen desde la perspectiva de oyentes, tornando opaca esa experiencia tan particular. Este trabajo tiene como objetivo aproximarse de la experiencia de vivir en el mundo cultural sin la apropiación de un lenguaje sistemática. Por lo tanto, se realizó un estudio de caso de una sorda que aprendió la Lengua Brasileña de Señales (LIBRAS) cuando adulta. La recolección de datos se llevó a cabo a través de una entrevista abierta, mediada por un intérprete voluntario. El análisis de las entrevistas fue guiado por el método fenomenológico de Giorgi y los datos interpretados desde la perspectiva de Merleau-Ponty. Los resultados se dividieron en dos grupos temáticos: El mundo sin sentido: vacío y soledad y El despertar de los sentidos, "una nueva vida". Las experiencias anteriores al dominio de un lenguaje sistemática fueran descritas como incomprensibles y vacías, permeadas por disociación y por experiencias dispersas. La entrevistada informó que después del aprendizaje, experimentó un cambio repentino en su relación con el mundo, empezando a darse cuenta de sentidos y gestos compartidos culturalmente. Se sugiere nuevos estudios para investigar la experiencia sensible y corporal de los sordos. Se destaca la importancia de la apropiación del lenguaje sistemática.
\end{abstract}

Palabras-clave: sordera, fenomenología-existencial, idioma, sentido, Merleau-Ponty.

Historicamente, a oralidade ocupa um papel central na compreensão do fenômeno linguístico em detrimento de outras formas de linguagem, tais como a língua de sinais. No século XVI, por exemplo, prevaleceu a ideia de que o pensamento abstrato se vinculava estritamente à oralidade (Sacks, 2010). Por volta de 1750, o abade francês De l'Epée, inconformado com a situação em que viviam alguns surdos (forçados a trabalhos desprezíveis e privados de educação formal), se aproximou deles, aprendeu sua língua, empreendeu a tentativa pioneira de sistematização de uma língua de sinais e possibilitou pela primeira vez que os surdos recebessem educação formal. De l'Epée é hoje conhecido como o "pai dos surdos". Suas ideias foram rapidamente difundidas na Europa e, mais tarde, nos EUA. Esse período é lembrado como uma "era dourada" na história da luta dos surdos por igualdade de direitos, pois marca seu 
ingresso nas instituições de ensino, apesar de as línguas de sinais ainda serem consideradas, à época, mímicas primitivas e limitadas (Sacks, 2010).

Em 1880, no Congresso Internacional de Educadores de Surdos, em Milão, as línguas de sinais foram proibidas. A partir de então, a oralização passou a ser uma imposição, o que causou muitos danos aos surdos, uma vez que a aquisição da oralidade costuma ser muito difícil e desgastante (Sacks, 2010). A resolução de 1880 desencadeou forte resistência de surdos, familiares e profissionais no mundo inteiro que defendiam que a surdez não é uma incompletude, mas uma diferença linguística que deve ser respeitada. Graças a essa resistência houve muitas conquistas. No Brasil foi aprovada a Lei $\mathrm{n}^{\circ}$ 10.436 apenas em 2002, que confere à Língua Brasileira de Sinais (LIBRAS) o estatuto de língua oficial e prevê que seu acesso seja garantido pelo Estado. Segundo Dizeu e Caporalli (2005), isso não eliminou a exclusão sofrida pelos surdos, pois a sociedade brasileira continua profundamente excludente e imperativamente oralista. Tal é o horizonte histórico sob o qual se perfilam as experiências de surdez.

Atualmente muito se tem avançado, há uma crescente preocupação do poder público e da sociedade em geral com a inclusão social dos surdos. Muito tem sido estudado sobre os aspectos médicos, linguísticos, educacionais, políticos e culturais que perpassam a questão da surdez, mas esse avanço não é perceptível em relação ao tratamento psicológico dessas pessoas. São poucos os profissionais de psicologia que se dispõem a enfrentar esse desafio, possivelmente pela dificuldade do aprendizado da LIBRAS, indispensável nesse trabalho (Gonçalves, 2012).

Bisol, Simoni e Sperb (2008) buscaram traçar o estado da arte das publicações em psicologia sobre a surdez e encontraram 34 artigos, publicados entre 1995 e 2005, que contemplam temáticas pertinentes à psicologia, cujos autores ao menos um fosse psicólogo. As autoras concluíram que se trata de uma publicação incipiente. Os artigos foram divididos de acordo com dois modelos de surdez: o clínicoterapêutico, que concebe a surdez como uma anomalia a ser corrigida, e o socioantropológico, que a compreende como uma diferença cultural e linguística. Seis dos artigos se enquadram no modelo clínico-terapêutico, 24 no sócio-antropológico e quatro na concepção psicanalítica. Apesar de a referida pesquisa ser relativamente antiga, não observamos um avanço nos estudos da área.

Muito do que se tem dito a respeito dos surdos é dito a partir da perspectiva dos ouvintes, quase sempre caracterizando a surdez como uma ausência, uma deficiência. Tais discursos não se preocupam em se aproximar da experiência mesma da surdez, mantendo uma atitude natural e objetificante diante do fenômeno: "a 
atitude natural não permite que vejamos o outro tal como ele se apresenta ao mundo, suprime-o" (Marques, 2008, p. 86). O estudo de Marques é um exemplo interessante de um trabalho que retoma a perspectiva da pessoa surda. $O$ autor busca compreender a experiência da surdez (dos surdos oralizados e sinalizados) tal como ela se mostra a partir de sua própria vivência (ele é surdo) e pautado nos referenciais teóricos da fenomenologia.

Outro exemplo de trabalho que parte da perspectiva das pessoas surdas é o artigo de Marin e Góes (2006), que apresenta uma análise histórico-cultural das falas de seis surdos a respeito de situações cotidianas no trabalho, em instituições comerciais e de saúde. As entrevistas explicitam uma grande dificuldade dos surdos em compreender regras e procedimentos do ambiente de trabalho, além de uma grande dependência de familiares na mediação dos mais simples e cotidianos diálogos, o que restringe de forma significativa suas relações, pois encontram poucos interlocutores que partilham do seu universo linguístico. Além disso, os discursos dos participantes do estudo denunciam a falta de intérpretes de LIBRAS atuando nos serviços de saúde (Marin \& Góes, 2006).

Dessa forma, fica evidente uma grande dificuldade de inclusão das pessoas surdas. É fundamental atentar para as especificidades das barreiras linguísticas enfrentadas pelos surdos, principalmente os que não optam pela oralização ou têm grande dificuldade com esta. Além do fato de a educação bilíngue (domínio da LIBRAS e do português) para surdos ainda ser falha, existem poucos ouvintes bilíngues, inviabilizando de um e de outro lado a concretização de um "projeto bilíngue" e da efetiva inclusão social dos surdos (Marin \& Góes, 2006).

Considerando que a Lei da LIBRAS é recente e a real inclusão é, ainda, distante, sabe-se que são muitos os casos de pessoas surdas que não têm domínio da língua portuguesa e, muitas vezes, aprendem a língua de sinais já em idade avançada. Deste modo, a questão que aqui se coloca é: como seria a experiência de um surdo que apenas tardiamente aprendeu a língua de sinais (sem domínio prévio da língua portuguesa) a ponto de se lembrar desta experiência?

Nosso objetivo é contribuir na direção de uma possível compreensão da experiência de viver no mundo sem a apropriação satisfatória de uma língua sistematizada, assim como trazer à luz um relato de experiência sobre o aprender da língua tardiamente, em um momento posterior aos esquecidos primeiros anos da infância. Para tanto, apresentamos o relato, em primeira pessoa, e algumas reflexões teóricas sobre uma surda que aprendeu a LIBRAS já adulta. Assim como Marques (2008) e Marin e Góes (2006), pretendemos dar visibilidade à experiência dos surdos, especialmente aos ditos "surdos 
pré-linguísticos", que são aqueles que nasceram ou ficaram surdos antes de aprender uma língua (Sacks, 2010).

\section{Surdez e Fenomenologia}

Nosso estudo de caso será orientado pela fenomenologia, pois esta busca descrever as experiências tal como se apresentam, antes de qualquer explicação, já que toda teorização é dependente da facticidade do mundo. $\mathrm{Na}$ busca de uma compreensão fenomenológica da surdez, não se trata de descartar tudo o que foi produzido sobre o tema nas mais diversas áreas do conhecimento, mas de compreender esses discursos a partir da experiência mesma da surdez.

Merleau-Ponty (2002) demonstra que mesmo tendo renunciado a toda a teologia, o saber científico, bem como o da psicologia moderna, concebe o homem adulto, são e civilizado, como dotado de uma "realização" ou "completude", uma "normalidade" fechada em si mesma. Nessa perspectiva, àqueles que faltasse qualquer qualidade desta dita normalidade estariam aquém ou seriam como seres humanos "inacabados". Toda a experiência no mundo é dada em uma unidade perceptiva, caracteristicamente ambígua, não havendo, portanto, um "acabamento" do humano. Nesse sentido é possível afirmar que não há nada que falte aos surdos para que alcancem o estatuto humano. Não faria sentido, por conseguinte, pensá-los como incompletos em relação aos ouvintes, não devemos buscar entendêlos pelo que pretensamente lhes faltaria, mas é preciso compreendêlos em suas especificidades vivenciais e potenciais. Tal como defende Marques (2008):

Tão somente a experiência que a mim cabe no entrelaçamento com o mundo, outros caminhos a mim se apresentarão como possíveis. Isso não me subjuga a uma inferioridade, mas a uma potencialidade que me coloca em condição de igualdade perante o mundo. (...) Essa investigação primeira de redução é que me vai apresentar a mim mesmo, não mais como o ser limitado na surdez, mas o ser que pela surdez se revela como uma pessoa que vê e contempla o mundo sob um outro prisma. (p. 28)

Se a proposta fenomenológica da compreensão da surdez discorda da visão clínico-terapêutica, também é diferente da perspectiva socioantropológica, apesar de reconhecer sua relevância política. Compreender o "Ser Surdo como essência e não como representação" (Marques, 2008, p. 64), significa conceber os surdos tal como se apresentam, e não apenas em seus aspectos linguísticos e culturais. 
Contudo, ele não desconsidera o fator cultural para a compreensão do tema: "a história, a cultura e a língua são aspectos que obviamente acompanham a pessoa na sua experiência com o mundo e na temporalidade" (Marques, 2008, p.23). Como diferença entre as perspectivas culturalista e fenomenológica, ele destaca que "a primeira ocorre a partir das experiências no mundo, das suas produções e representações, a segunda ocorre nas suas potencialidades, na sua consistência, nas formas como o corpo se "manifesta" no mundo" (Marques, 2008, p.25). O autor aborda a questão especialmente a partir do conceito de corpo em MerleauPonty, se opondo às noções mecanicistas, ao colocar o corpo próprio como centro da existência. Marques defende que a compreensão da surdez suplanta o apontamento da diferença linguística ou morfológica entre surdos e ouvintes, trata-se de uma diferença perceptual e de um modo de ser no mundo específico, com seu ponto de vista próprio.

Marques (2008) aponta que os estudos linguísticos geralmente se restringem à linguagem verbal e à palavra, por outro lado, a fenomenologia da linguagem de Merleau-Ponty aborda uma dimensão mais profunda da questão, por meio da explicitação do problema da expressão. Para Merleau-Ponty, a linguagem não se reduz ao verbal ou à oralidade, não estando vinculada ao pensamento, mas à existência. A expressão é o que excede da experiência perceptiva em relação ao que já foi dito (Merleau-Ponty, 1945/2011), trata-se de uma criação de sentido que acontece na fala oral, mas também, por exemplo, nas artes, nas diversas expressões corporais e, sem dúvidas, nas línguas de sinais. Dentro desta perspectiva, pode se considerar que as diferentes línguas são "várias maneiras, para o corpo humano, de celebrar o mundo e finalmente de vivê-lo" (Merleau-Ponty, 1945/2011, p. 255).

\section{Método}

Este trabalho é um estudo de caso exploratório que busca uma primeira aproximação ao fenômeno da surdez enquanto vivência. Para tanto, foi escolhida uma abordagem mista do problema, o estudo de caso e a análise fenomenológica. Segundo Yin (2010), os estudos de caso são uma modalidade recomendável de pesquisa quando o investigador tem pouco ou nenhum controle sobre os eventos e pretende investigar em termos de "por que" ou "como" fenômenos complexos da vida real (Yin, 2010). Para o autor, o estudo de um caso não deve ser considerado uma "amostragem" de determinado fenômeno, mas deve problematizar e enriquecer as teorias a respeito. Por não ser possível destacar o caso de seu 
contexto social, tal estudo permite que as questões contextuais sejam explicitadas.

Existem diversas formas de coleta de dados nos estudos de caso, aqui foi escolhida a entrevista, pois considerou-se que a questão da pesquisa seria melhor respondida por meio de um relato. Yin (2010) adverte que o pesquisador deve se apropriar da literatura específica relativa ao método escolhido. Nesse caso, nos orientamos pelo método fenomenológico de investigação em psicologia de Amedeo Giorgi, pois este permite descrever os sentidos da vivência relatada. Usou-se uma adaptação desse método, conforme justificaremos a seguir.

Sabe-se que o pesquisador não é neutro em relação à experiência investigada, portanto, para poder se aproximar de fato da experiência relatada, em todas as etapas mantivemos uma postura de redução fenomenológica, que consiste em um esforço (nunca acabado) por abster-se, momentaneamente, de qualquer saber a priori sobre o que é ser surdo, como se entrássemos em contato com tal experiência pela primeira vez.

\section{Procedimentos}

O projeto dessa pesquisa foi aprovado pelo Comitê de Ética em Pesquisa em Seres Humanos (CEP) da Universidade Federal do Paraná (UFPR), sob o registro CAAE 19386813.1.0000.0102. A coleta de dados se deu por meio de uma entrevista aberta, com a seguinte pergunta disparadora: "Como você descreve a sua vida antes de aprender a língua de sinais?". A entrevista aconteceu no Centro de Psicologia Aplicada (CPA) da UFPR e contou com um intérprete voluntário de LIBRAS. A entrevistada assinou um Termo de Consentimento Livre e Esclarecido (TCLE) que garante que o material coletado seja tratado com sigilo. Houve registro em áudio da tradução do intérprete. Após a transcrição, a entrevista foi apresentada à participante para revisão, com o intuito de minimizar possíveis equívocos de tradução.

\section{Análise dos Dados}

Análise da entrevista buscou seguir as três primeiras etapas do método de Giorgi. A partir da transcrição integral da entrevista, o método propõe quatro etapas: o estabelecimento do sentido geral, a identificação de unidades de significado (o texto foi separado cada vez que a fala da entrevistada trazia um novo sentido), a tradução das unidades de significado em expressões de caráter psicológico, 
determinação da estrutura geral de significados psicológicos (Giorgi \& Souza, 2010).

A última etapa não foi realizada neste trabalho, pois se trata do agrupamento em unidades de sentido quando consideradas um número maior de entrevistas, com o objetivo de aplicar a variação livre imaginativa, não sendo possível de ser aplicada no estudo de caso. Os sentidos traduzidos no terceiro passo foram agrupados em um único texto, que foi articulado à bibliografia suscitada pela fala da entrevistada, compondo a discussão do trabalho. Nem todos os temas trazidos pela entrevistada couberam no espaço e no escopo deste trabalho, deste modo, a tradução da entrevista foi reorganizada: foram priorizados os sentidos que se referiam à pergunta da pesquisa e foram agrupados outros que se referiam a temas próximos, de forma a facilitar a leitura e a discussão. As reflexões de Husserl e Merleau-Ponty foram utilizadas para dar densidade às interpretações, devido à possibilidade que estes pensadores abrem para se refletir sobre a experiência da linguagem enquanto experiência e não apenas como racionalidade, permitindo o aprofundamento do que se mostra como vivência no relato da participante.

\section{Participante}

Fátima (nome fictício) perdeu a audição com um ano e seis meses de idade, em decorrência de uma meningite. Foi criada por sua avó, a quem considerava como mãe. A avó faleceu quando ela tinha treze anos. Vivia com elas uma prima adotiva, dez anos mais velha, com quem Fátima continuou morando depois da morte da avó, até seus 28 anos, quando se casou. No momento da entrevista, Fátima tinha 56 anos. Ela estudou até o quarto ano fundamental em uma escola oralista para surdos. Aos 37 anos, cursou um supletivo do primeiro grau e outro do magistério e, mais tarde, uma faculdade de pedagogia, ambos em instituições para ouvintes. Esta última contava com intérpretes de língua de sinais. Também por volta dos 37 anos, conjuntamente com mais alguns surdos, iniciou um grupo de estudos sobre língua de sinais. Aos 40, passou a frequentar um curso de instrutores de LIBRAS, quando a aprendeu de fato e estudou sobre a cultura surda. Até então, ela se comunicava por meio de uma língua de sinais mais simples, menos sistematizada. Fátima também é graduada em Letras/LIBRAS.

\section{Resultados e Discussão}

Os resultados serão apresentados em dois grandes grupos temáticos: $O$ mundo sem sentido: vazio e solidão e $O$ despertar aos sentidos: 
"uma nova vida". A discussão foi dividida dessa forma porque percebeu-se, no relato de Fátima, uma mudança significativa em sua relação com o mundo quando aprendeu a língua de sinais, vivendo um despertar aos sentidos. Ela narrou que antes de aprender a LIBRAS se sentia sozinha, vazia e não compreendia o que se passava ao seu redor. Descreveu também, com comoção, que o mundo se tornou mais claro para ela quando aprendeu a língua de sinais.

\section{O Mundo sem Sentido: Vazio e Solidão}

Ao relatar sua infância, quando ainda não havia aprendido nenhuma língua sistematizada, Fátima descreveu sua experiência de mundo calcada em uma falta de sentido, permeada por vazio e solidão. Ela contou não saber muito sobre sua infância, o que lhe aconteceu ou como se comunicava com as pessoas, por exemplo. Afirmou que sempre perguntava aos seus familiares sobre sua infância, porém, estes também não sabiam responder às suas indagações: "então eu acabei perdendo muito essa minha história, de quando eu era pequena".

Embora frequentemente caracterizar sua vida antes de aprender a língua de sinais como incompreensível e desprovida de sentido, Fátima relatou vários episódios desse período, descrevendo-os em seus aspectos vivenciais. Contou que sua avó nem tinha grande preocupação em se comunicar com ela, nem tampouco possuía informações sobre língua de sinais, pouco difundida na época. Os outros familiares usavam alguns gestos para se comunicar com ela, mas ela os considerava muito repetitivos. De acordo com Husserl (1935/1993), as crianças nascem em um mundo de sentidos culturais para o qual não estão desde sempre despertas. Esse despertar é efetuado pelos adultos e passa, fundamentalmente, pela linguagem (Freitas, 2015). A fala que os adultos dirigem à criança é centrada nela e possui papel fundamental no despertar aos sentidos. No relato de Fátima fica claro o quanto a comunicação com seus familiares é percebida hoje por ela como insuficiente, podemos dizer que não havia em seu meio quem assumisse seu ponto de vista sobre 0 mundo.

Ao falar sobre a aprendizagem da língua, Merleau-Ponty (2006) se debruça sobre o fenômeno da infância. O autor, em seus estudos sobre linguagem, ressalta que é necessária uma imersão no referido universo linguístico para que a língua se ensine por si mesma: "o todo da língua falada à sua volta a tragaria [a criança] ${ }^{1}$ qual turbilhão, tentá-la-ia por suas articulações internas e a conduziria quase até o momento em que todo esse ruído significará algo" (Merleau-Ponty, 1961/2013, p. 61). Mas, através do relato de Fátima, percebemos que isso só ocorreria se "o todo da língua falada" 
pudesse ser efetivamente percebido por quem aprende, o que não ocorreu com ela, que cresceu surda em um ambiente linguístico sonoro.

Em vários aspectos o relato de Fátima lembra a famosa história de Helen Keller, escritora e ativista social surda e cega, que viveu nos EUA entre 1880 e 1968. Como a entrevistada, Helen ficou surda com aproximadamente um ano e meio de idade e viveu em uma família de ouvintes onde não se usava a língua de sinais. Ambas descrevem uma importante transformação no modo de se relacionar com o mundo a partir do momento em que aprenderam a língua de sinais. No caso de Helen, por ser também cega, aprendeu ainda criança a língua de sinais manual (língua de sinais para cegos) em casa, com a educadora Anne Sullivan. Em seu diário, Helen Keller descreve várias memórias referentes ao período anterior à aprendizagem da língua de sinais manual: "guardo muitos incidentes daqueles primeiros anos fixados na memória, isolados, mas claros e distintos, tornando ainda mais intenso o sentido daquela vida sem dias, sem objetivos, silenciosa" (Keller, 2008, p.12).

Ao relatar como se sentia na infância, Fátima citou o exemplo de como experimentou a solidão e a falta de compreensão dos atos e gestos nas brincadeiras de criança. Ao tentar se incluir nas brincadeiras, imitava o gestual das outras crianças, especialmente 0 labial, mesmo não compreendendo o que fazia. Percebia que as outras crianças a provocavam e riam dela, entretanto, não entendia exatamente o que acontecia e o seu porquê. Merleau-Ponty (2006) aponta que, nas crianças, a imitação tem grande relevância na aprendizagem da língua materna. Primeiro a criança imita o gesto de falar, de se comunicar e, aos poucos vai se apropriando dos sentidos compartilhados em sua cultura. $\mathrm{Na}$ imitação das crianças, há uma apropriação cada vez maior do sentido do gesto imitado. Já na vida de Fátima, a imitação seguiu sendo uma busca por uma inserção no mundo, porém, carente de sentido.

Baseado em Guilhaume, Merleau-Ponty, 2006) afirma que o fenômeno da imitação não parte de nenhum tipo de representação dos movimentos alheios. Inicialmente, as crianças não têm consciência do próprio corpo, mas das coisas do mundo, "a imitação só se entende como encontro de duas ações em torno do mesmo objeto: imitar não é fazer como outrem, mas chegar ao mesmo resultado" (Merleau-Ponty, 2006, p. 25). Não se trata de imitação do caminho do gesto, mas em direção ao resultado global, não do movimento corporal do outro, mas de um comportamento. Todavia, a imitação de um comportamento pressupõe a compreensão do seu sentido, o que Fátima não possuía. Os movimentos labiais das outras crianças eram os meios pelos quais estas efetuavam o gesto, cujo resultado era a fala oral, inapreensível por ela. Fátima disse que não tinha linguagem, que parecia que seu "cérebro não funcionava". Ela 
se sentia "como o menino lobo": "Parecia que eu estava simplesmente copiando o que as pessoas faziam, eu nem percebia... Hoje eu entendo isso!". Hoje, com o domínio da linguagem, Fátima pode resignificar suas vivências da infância, podendo nomeá-las como nebulosas e confusas.

Merleau-Ponty (2006) marca a importância da imitação para a imersão no mundo humano. Aproximadamente entre seis e doze meses, a criança imita o gesto de falar e de se comunicar, mas sem a apropriação do sentido do que é imitado, imergindo na linguagem. $O$ autor aponta ainda que os primeiros balbucios são parecidos em todas as crianças, qualquer que seja a língua materna, mas por meio da fala, os adultos oferecem a direção da imersão linguística, permitindo a emergência de um mundo.

As imitações vazias de Fátima não se restringiam ao gesto linguístico, mas alcançaram as dimensões sociais de sua vida. Ela relatou, por exemplo, que se casou "pra poder copiar o padrão da sociedade" uma vez que ela e seu marido, também surdo (hoje não são mais casados), não se amavam. As imitações de Fátima revelam um esforço para se inserir na sociedade, por mais que ela não se apropriasse dos sentidos dos gestos imitados. No relato de Helen Keller também se encontra a imitação de gestos humanos vazios de sentido: "Pelo mesmo instinto de imitação, eu dobrava as roupas que vinham da lavanderia e separava as minhas, alimentava os perus, costurava olhos de conta no rosto de minha boneca e fazia muitas outras coisas das quais eu tinha lembrança tátil" (Keller, 2008, p.427, Apêndice I). Helen também descreve o papel da imitação no aprendizado da língua. Quando Anne Sullivan começou the ensinando a soletrar palavras com o alfabeto manual, ela primeiro tão-só a imitava, apenas mais tarde começou a compreender que cada coisa tinha um nome.

$\mathrm{Na}$ escola onde Fátima estudou desde os quatro anos, ensinava-se apenas a língua oral que deveria ser copiada pelos alunos. As crianças não a utilizavam em seu cotidiano, simplesmente copiavam a oralização sem compreender o porquê. Ela estudou nessa escola durante dez anos e considerava ter se sentido sempre muito vazia e que não entendia as frases em português. Esse foi um período que precedeu a Lei da LIBRAS e as discussões sobre a educação bilíngue no Brasil. Não pretendemos aqui traçar uma discussão aprofundada a respeito dos métodos empregados na educação dos surdos, mas não podemos deixar de comentar que a experiência de Fátima aponta para um modo da existência relacionado à imposição do método oralista, pois ela afirma não encontrar sentido nas imitações que foi obrigada a realizar, a língua portuguesa não possuía relação alguma com suas experiências. O relato de Fátima remete aos depoimentos do estudo de Marin e Góes (2006), que interpretam a sensação que alguns surdos relatam ao se referirem ao seu passado escolar, de se 
sentirem como "estrangeiros, forasteiros, exilados", (Marin \& Góes, 2006, p. 243).

Merleau-Ponty (1945/2011) demonstra que a experiência perceptiva e linguagem não podem ser pensadas separadamente. Se Fátima não encontrava relação entre as palavras em português e suas vivências, era porque não podia compreender essas segmentações auditivas e nem se expressar na língua portuguesa. Tal compreensão sobre a expressão está calcada no foco sobre o mundo-da-vida, abordado pela fenomenologia desde Husserl, onde encontra-se o fundamento de todo conhecimento, sempre experienciado de modo antepredicativo.

Fátima teve acesso à língua de sinais apenas na idade adulta, pois sua língua de instrução foi a portuguesa. Ela descreveu sua relação com esta última como uma experiência de contato apenas com "palavras soltas" e descontextualizadas. Era como se seu pensamento fosse um "quebra-cabeça", que não conseguia compreender. Merleau-Ponty (1961/2013), apoiado na concepção de sentido diacrítico de Saussure, afirma que os signos não têm significação positiva, mas apenas em relação uns aos outros, compondo a totalidade da língua. Dessa maneira, não há mesmo o menor sentido em ensinar a crianças surdas fragmentos de uma língua da qual elas não poderão apreender o todo, onde as palavras estarão sempre soltas e descontextualizadas.

Fátima narrou que se sentia "reprimida" na escola, assim como na vizinhança. Relatou, de modo enfático, que the era dito "não" frente a todas as tentativas de explorar o mundo e que não compreendia porque lhe era proibido até mesmo pegar ou tocar nos objetos:

Eu perguntava, tinha curiosidade, queria cheirar as coisas, por exemplo, esse copo de água que eu peguei aqui... minha prima falava 'não, isso é feio fazer, não faça!', mas eu não entendia porque, ela tentava explicar, eu não tinha entendimento, por exemplo, do certo e do errado, porque eu podia fazer algumas coisas e outras não.

$\mathrm{Na}$ casa de seus tios, em uma tentativa de explorar e compreender $\mathrm{o}$ mundo, era comum que cheirasse todas as coisas, o que resultava em repreensões. À Fátima era vedada a compreensão da língua e também dos objetos culturais, pelos quais ela teria indícios do mundo humano e de outrem. As compreensões de si, do outro e do mundo encontram-se, na filosofia de Merleau-Ponty (1945/2011), intimamente imbricadas: "assim como a natureza penetra até no centro de minha vida pessoal e entrelaça-se a ela, os comportamentos também descem na natureza e depositam-se nela sob a forma de um mundo cultural" (p. 465). Tais comportamentos são chamados pelo autor de segmentações, surgem dos atos 
espontâneos dos homens e passam a levar "a existência anônima das coisas" (p. 465). São as "coisas", objetos culturais, que denunciam a todo tempo a existência de outrem.

Descobrir o mundo é descobrir a si-mesmo e ao outro. Merleau-Ponty (2011) aborda o problema da existência de outrem a partir da noção de consciência perceptiva. Ele reconhece que a inerência ao mundoda-vida e a intersubjetividade são estruturas da existência. A consciência não é constituinte do outro e do mundo, mas uma perspectiva do mesmo mundo onde consciências coexistem (MerleauPonty, 1945/2011):

$\mathrm{Na}$ realidade, outrem não está cercado em minha perspectiva sobre o mundo porque esta mesma perspectiva não tem limites definidos, porque ela escorrega espontaneamente na perspectiva de outrem e porque elas são ambas recolhidas em um só mundo do qual participamos todos enquanto sujeitos anônimos da percepção (p. 473).

Nesse sentido pode-se falar em uma co-percepção, em uma compreensão de mundo partilhada. No caso de Fátima, ao contrário, nota-se uma incompreensão de si que não pode ser destacada de sua relação com o mundo e com os outros, permeada por questionamentos, pois como dissemos anteriormente, seu ponto de vista sobre o mundo não era colocado como possibilidade pelos outros significativos nas relações que vivia.

Aproximadamente aos 37 anos, Fátima e algumas amigas surdas organizaram um grupo de estudos sobre língua de sinais. Com o grupo ela percebeu a importância de os surdos se comunicarem, se compreenderem e trocar experiências. Mais surdos passaram a frequentar o grupo, onde uns se identificavam com as dificuldades dos outros: "(...) muitos surdos tinham problemas igual a gente. Mas a gente não sabia o que era língua, a gente não tinha esse conhecimento, essa compreensão, a gente não aprendeu".

Dizeu e Caporali (2005) consideram relevante a convivência entre os surdos, pois a participação em uma comunidade mostra à pessoa surda que ela tem condições de se desenvolver normalmente, que pode abandonar a identidade de deficiente auditiva em benefício da identidade de surda com plenas possibilidades de desenvolvimento cognitivo e social. Ao se questionar sobre os motivos da aproximação entre os surdos, Marques (2008) aponta que esta fundamenta-se no fato de que eles percebem o mundo de forma semelhante, e não apenas no fato de compartilharem a mesma língua:

(...) a experiência da surdez apresenta o corpo não como uma pessoa anatomicamente diferenciada, mas como uma pessoa com funcionalidades sensoriais e perceptuais que lhe 
constituem uma interpretação e interação com o mundo específicas, que quando inseridas no mundo se transformam e transformam esse mundo (p. 29).

Ou, em termos existenciais, é adentrar no mundo, pois o mundo "é esse meio onde cada presença pode ser indefinidamente confirmada pelas outras percepções, e da outra parte a reenvia à um meio que pode igualmente ser explorado sem fim" (Barbaras, 1997, p. 59). O mundo que carece de sentido é para Fátima, um mundo de perguntas, sem possibilidade de respostas. É um mundo de solidão, sem identidade que começa a ser resgatada com a inserção em uma comunidade. Hoje, ela nega a terminologia "d.a.", deficiente auditivo, "não sou deficiente auditivo, sou surda!".

Aos 37 anos Fátima decidiu voltar a estudar, pois só havia cursado até a quarta série. Ela sabia muito pouco de língua de sinais e não sabia ler nem escrever. Nossa entrevistada relatou que apesar das suas dificuldades de compreensão, desejava experimentar e aproveitar a oportunidade de voltar a estudar. Ela e duas amigas que a acompanharam, tiveram problemas para se inscrever no curso e não foram ajudadas pelos ouvintes, que lhes diziam que elas não precisavam estudar, pois seria muito difícil. Mas, mesmo assim, insistiram. Quando a professora percebeu que eram surdas, apenas Ihes aferia uma nota para que fossem aprovadas. Elas entendiam poucas palavras, como se fossem "códigos": viam uma palavra no texto, assinalavam a mesma palavra na prova e eram aprovadas, mas não entendiam os conteúdos. Fátima contou que o supletivo foi bastante difícil. Ao concluir o primeiro grau, ela ainda se sentia vazia: "Pra que mostrar que eu tenho o primeiro grau? Mas por dentro parece que eu não tenho nada!". Depois também cursou um supletivo do magistério.

Como as outras experiências que relatou, esta última também é descrita como vazia e sem sentido. Fátima contou que reproduzia inúmeros gestos comuns na sociedade: brincava, movia os lábios, concluiu etapas da educação formal e se casou. Mas, antes de aprender a língua de sinais, não havia despertado aos sentidos de nenhum desses gestos, eles se apresentavam discretamente, desconexos e sem sentido.

\section{O Despertar aos Sentidos: "Uma Nova Vida"}

Quando Fátima tinha aproximadamente 40 anos, soube do início de um curso de instrutores de LIBRAS, cujo objetivo era que os surdos aprendessem sobre metodologia de ensino da língua. Foi quando aprendeu a LIBRAS. A respeito dessa experiência, narrou: 
Eu comecei a me desenvolver e ver! Parecia que eu estava no primeiro ano de novo, tudo de novo, porque eu estava começando a entender as coisas! Estavam começando a ficar claras pra mim! Porque era dado em língua de sinais. Porque antes, até então minha comunicação era muito oralizada, aí então que eu comecei a usar a língua. Foi explicado sobre os surdos, foi explicado sobre língua de sinais. Eu me emocionei muito com aquilo tudo! Era como se eu tivesse começando a me desenvolver, eu tinha vontade de aprender! E eu senti que eu estava me recuperando, estava conseguindo recuperar o tempo perdido. Então eu comecei a falar: isso! É uma nova vida pra mim agora!

Ao compreender a língua de sinais manual, Keller (2008) descreve uma comoção semelhante:

De repente senti uma consciência envolta em nevoeiro, como algo esquecido - o eletrizar de um pensamento que voltava; e de algum modo o mistério da linguagem foi revelado a mim. Soube então que "á-g-u-a" significava a maravilhosa coisa fresca que fluía sobre minha mão. Aquela palavra viva despertou minha alma, deu-lhe luz, esperança, alegria, enfim, libertou-a. (...) E quanto mais manejava coisas e aprendia seus nomes e usos, mais alegre e autoconfiante tornava-se minha noção de parentesco com o resto do mundo (p.21).

Ambas falam de uma súbita compreensão de suas experiências e do mundo no momento em que aprenderam a língua de sinais: não apenas um despertar aos sentidos humanos, mas um jorrar de sentidos, além de uma nova proximidade com o mundo. O que Fátima e Helen encontram ao aprender a língua de sinais não é um novo mundo, no sentido de que o que se viveu antes da linguagem não existiu, mas é um novo mundo pelo despertar dos sentidos e pelo seu pertencimento. Se elas relatam que passaram "de repente" a compreender o mundo, é porque agora os sentidos o abrem, tal como o cirurgião abre um corpo (Merleau-Ponty, 1964/1992). Com a abertura de um novo horizonte de sentidos, foi possível um deslocamento do olhar, novas produções de relações infinitas entre os sentidos, a significação de suas experiências.

Esse despertar descrito por Fátima e por Helen é muito diverso do que acontece com as crianças pequenas. Se considerarmos como Merleau-Ponty (1945/2011), que a linguagem está fundamentalmente relacionada à experiência perceptiva, vale ponderar que assim como Helen, Fátima aprendeu a língua de sinais quando já habitava o mundo há muito tempo, porém um mundo onde as experiências são relatadas como esparsas, nebulosas, dissociadas 
umas das outras e vazias de sentido. As crianças pequenas, ao mesmo tempo em que imergem na linguagem vão descobrindo a si e ao mundo. Essa comoção e esse encantamento com a linguagem descritos por Fátima e Helen, se referem ao despertar das duas aos sentidos do mundo, mundo ao qual já estavam sempre imbricadas, porém com um entrelaçamento fortemente marcado pela hylé, onde os dados sensíveis da percepção eram colocados como um quebracabeças sinestésico distinguidos por uma espécie de névoa e de suspensão. Na passagem da percepção para a criação de sentido, não há uma mudança de mundo, é como se a expressão liberasse o sentido do mundo, em um processo interminável (Merleau-Ponty, 1961/2013).

Merleau-Ponty (1945/2011) discrimina duas camadas da linguagem, a fala falante e a fala falada. A fala falante se refere ao momento de emergência de novos sentidos quando a experiência perceptiva excede o que já foi dito e há a expressão significativa autêntica. Sendo expressos, os novos significados são como que sedimentados e compartilhados, emergindo como fala falada. O movimento de fala falante e fala falada constitui um universo linguístico e cultural sempre vivo: "As significações disponíveis, quer dizer, os atos de expressão anteriores, estabelecem entre os sujeitos falantes um mundo comum ao qual a fala atual e nova se refere, assim como o gesto ao mundo sensível" (Merleau-Ponty, 1945/2011, p.253). As línguas, mais especificamente, são formas de linguagem compartilhadas por determinados grupos de pessoas. A sistematização de uma língua é uma formalização da fala falada.

Ao longo de sua obra, Merleau-Ponty enfatiza cada vez mais o aspecto segmentado da linguagem (Cardim, 2012). A concepção de fala falada é fundamental para a compreensão do que Fátima chama de "uma nova vida", pois esse momento se refere justamente a sua imersão em um mundo de sentidos compartilhados em sua cultura, no qual não apenas as coisas "falavam", mas ela também pôde criar seu próprio discurso. A criação de novos sentidos sempre ocorre em um universo linguístico já disponível, ao qual Fátima tinha um acesso muito precário antes de aprender a língua de sinais.

Fátima decidiu cursar pedagogia. Na faculdade, ganhou uma bolsa de estudos e em troca dava aulas de LIBRAS. Contou que sentia muita dificuldade em ministrar as aulas e que às vezes os alunos riam dela: "Eu percebia, mas eu não entendia. A gente [os surdos] tem muito o visual, a gente acaba percebendo essas coisas". Fátima relatou que também enfrentou dificuldades por sua aprendizagem ali não ser clara nem de qualidade. Contou que se sentia sozinha e que por ser surda, era sempre excluída dos grupos de trabalho.

Durante os seis primeiros meses, não havia um intérprete com ela. Quando esse chegou, viveu uma separação entre o intérprete e o professor e entre ela e o professor. Como aprender se ao focar a 
atenção no professor, deixava de acompanhar o intérprete e, se olhasse para o intérprete, não prestava atenção no professor? Fátima já podia compreender o mundo e dar sentido às suas experiências por meio da língua de sinais, mas se graduou em um contexto em que tudo era ensinado em língua portuguesa. Com o passar do tempo, conseguiu concluir a faculdade. Contou que queria um diploma para mostrar às pessoas que tinha "qualidade" e que era "superior", porém não se sentia assim, sentia como se ainda lhe faltasse algo.

$\mathrm{Na}$ entrevista, Fátima apresentou uma rica discussão sobre o bilinguismo que não cabe nos limites desse trabalho. De forma bem resumida, ela defende que é preciso priorizar o ensino da língua de sinais porque as crianças surdas são visuais, veem o "mundo por imagens". Por isso, a LIBRAS deve ser aprendida primeiro e depois a língua portuguesa, que não deve ser negligenciada no ensino bilíngue. Dizeu e Caporali (2005) enfatizam a importância de as crianças surdas serem expostas à língua de sinais o mais cedo possível. Tal proposta requer um diagnóstico precoce e a opção dos pais por tal modalidade linguística, o que nem sempre acontece. Depois de aprender a LIBRAS, a criança estará em condições de aprender uma segunda língua, como o português.

Depois de se graduar em pedagogia, Fátima cursou a faculdade de Letras/LIBRAS e contou que desde então pôde compreender melhor o mundo: "Eu tenho mais respostas pras coisas. Antes parecia que meu mundo era cheio de perguntas, agora eu consigo respondê-las mais, essas perguntas diminuíram".

\section{Considerações Finais}

A partir da discussão do relato de Fátima, foi possível uma aproximação à experiência da surdez em seus aspectos existenciais, especialmente de sua condição tão especial, na qual o ensino da língua de sinais foi negligenciado. $O$ mundo $e$ as experiências perceptivas se apresentaram na ausência do domínio de uma língua que permitisse o desvelamento do gesto no curso da linguagem, como incompreensíveis e vazios, permeados por buracos e experiências esparsas.

O aprendizado da língua de sinais para Fátima, assim como foi para Helen Keller, guarda semelhanças com a aprendizagem da fala pela criança ouvinte, pois ambos aprendizados se referem a um despertar ao mundo dos sentidos. Porém, os dois processos não se igualam. 0 despertar do mundo nas crianças é efetuado pelos adultos, que inicialmente não são percebidos pela criança como separados dela. As crianças vão imitando as falas que the são dirigidas e, aos poucos, vão imergindo na comunidade que pertencem (Freitas, 2015). 
Enquanto a imitação tem na vida das crianças o importante papel de inseri-las no mundo dos gestos humanos, na vida de Fátima, a imitação fracassou, pois ela se manteve durante muito tempo buscando uma inserção que the era incompreensível, uma vez que sua imitação carecia de significação, assim como carecia de um partilhar da camada do sensível no uso do próprio corpo. Suas imitações eram vazias não por ser surda, mas por não estar inserida em uma comunidade que conseguisse se colocar em seu ponto de vista, abrindo-Ihe uma perspectiva. Ficou evidente que a impossibilidade de se compartilhar os sentidos culturais trouxe restrições na relação com o mundo e com os outros, descritas por ela como solidão, vazio e falta de compreensão sobre o que acontecia, 0 que de algum modo é também relatado por Dizeu e Caporali (2005), merecendo estudos mais aprofundados.

Viu-se que experiência perceptiva e linguagem estão estruturalmente articuladas na existência, pois Fátima passou a compreender 0 mundo e suas experiências de forma abrupta ao aprender a LIBRAS, podendo dar sentido às suas incontáveis experiências perceptivas, configurando-as, finalmente, como linguagem. Nesse momento, contudo, já percebia uma diferenciação entre si e os outros, apesar de essa condição ser permeada por questionamentos sem sombra de resposta. Ao contrário das crianças ouvintes que ao mesmo tempo em que despertam aos sentidos descobrem o mundo, Fátima já articulava um mundo muito tempo antes de compreender seus sentidos culturais, pela imitação vazia. A diferença talvez repouse no fato de que ela se manteve em um vínculo mais fortemente cinestésico, ou em suas palavras, marcado pelo aspecto visual, o que merece ser contemplado por outros estudos fenomenológicos mais aprofundadamente.

Marques (2008) esboçou possíveis contribuições da fenomenologia para a educação dos surdos. Ele é ousado ao aproximar a fenomenologia às suas formas linguísticas: "o método fenomenológico é semelhante à forma como as pessoas surdas apreendem o mundo; a própria língua de sinais se apresenta de forma descritiva" (Marques, 2008, p. 26). O aspecto da abertura a partir de uma estrutura do visível e da corporeidade, tão potente e explícita nos surdos, é um tema que fugiu ao escopo do presente trabalho, porém aparece como campo fundamental para trabalhos posteriores, pois uma compreensão mais profunda desta experiência pode ter implicações decisivas para a educação desta população, por exemplo. Tendo a especificidade da relação com a corporeidade emergido apenas ao longo da análise da entrevista, notamos uma opacidade deste fenômeno para nós, pesquisadoras do presente trabalho. Tal opacidade se deve, provavelmente, ao fato de que somos ouvintes. 
Não pretendemos, com esse trabalho, fazer uma generalização da experiência investigada, mesmo que sejam notados aspectos da vivência de Fátima que são semelhantes à história de Helen. Contudo, como estudo de caso, o presente trabalho desvela não apenas a necessidade de se compreender cada pessoa em suas especificidades vivenciais, a partir de sua experiência em primeira pessoa, mas também permite tornar visível a experiência de se viver no mundo cultural sem a apropriação de uma língua sistematizada de forma mais densa. A experiência da língua é uma experiência no mundo de uma cultura e, portanto, diz respeito a todos nós.

Compreender a experiência de uma pessoa surda que aprende a língua de sinais apenas em uma idade avançada, pode nos auxiliar a entender melhor variadas experiências que concernem o aprendizado e uso da linguagem, como por exemplo, a de crianças e adultos surdos que ainda não conseguem expressar suas dificuldades em um mundo no qual ainda não estão totalmente inseridos. Por fim e não menos importante, revela à sociedade e aos profissionais que trabalham com surdos que sua experiência parte não de uma falta, mas que é marcada por um modo de sensibilidade ao mundo que lhes é próprio e não pode ser compreendido a partir dos parâmetros das vivências de mundo e de linguagem das pessoas ouvintes.

\section{Referências}

Barbaras, R. (1997). Merleau-Ponty. Paris: Elipses.

Bisol, C. A., Simoni, J., \& Sperb, T. (2008). Contribuições da Psicologia Brasileira para o Estudo da Surdez. Psicologia: reflexão e crítica, 21, 392-400. doi: 10.1590/S010279722008000300007

Cardim, L. N. (2012). "A ebulição na massa d'água" ou a linguagem segundo Merleau-Ponty. Revista dois pontos, 9(1), 35-69. doi: 10.5380/dp.v9i1.29092

Dizeu, L. C. T. B., \& Caporali, S. A. (2005). A língua de sinais constituindo o sujeito como surdo. Educação \& Sociedade, 26, 583-597. doi: 10.1590/S0101-73302005000200014

Freitas, J. L. (2015). A criança sob o olhar fenomenológico: o despertar do mundo-da-vida. In A. M. L. C. de Feijoo, \& E. L. Feijoo. (Org.). Ser criança: Uma compreensão existencial da experiência infantil (pp. 35-52). Rio de Janeiro: IFEN.

Giorgi, A., \& Souza, D. (2010). Métodos Fenomenológicos de Investigação em Psicologia. Lisboa: Editora Século.

Gonçalves. P. C. S. (março, 2012). Atendimento Psicológico para Surdos. Revista Virtual de Cultura Surda e Diversidade, edição 9. Recuperado de http://editora-araraazul.com.br/site/revista_edicoes/detalhes/42 
Husserl, E. (1993). L'enfant. La première Einfühlung. Alter, 1, 265270.(Tradução de N. Depraz). (Manuscrito original de 1935).

Keller, H. (2008). A história da minha vida. Rio de Janeiro: José Olímpio.

Marin, C. R., \& Góes, M. C. R. (2006). A experiência de pessoas surdas em esferas de atividade do cotidiano. Cadernos CEDES, 26, 231-249. doi: 10.1590/S0101-32622006000200007

Marques, R. R. (2008). A experiência de ser surdo: uma descrição fenomenológica (Tese de Doutorado não publicada). Universidade Federal de Santa Catarina, Florianópolis.

Merleau-Ponty, M. (1992). O visível e o invisível (A. Gianotti, \& A. Mora, Trad.). São Paulo: Perspectiva. (Texto original publicado em 1964).

Merleau-Ponty, M. (2002). Palestras. (A. Morão, Trad.) Lisboa: edições70.

Merleau-Ponty, M. (2006). Psicologia e pedagogia da criança: Curso da Sorbonne. São Paulo: Martins Fontes. (Texto original publicado em 2001).

Merleau-Ponty, M. (2011). Fenomenologia da Percepção. São Paulo; Martins Fontes. (Texto original publicado em 1945).

Merleau-Ponty, M. (2013). A linguagem indireta e as vozes do silêncio. In M. Merleau-Ponty $O$ olho e o espírito (pp. 13-46). (P. Neves, \& M. E. G. G. Pereira, Trad). São Paulo: Cosac \& Naify. (Texto original publicado em 1961).

Sacks, O. W. (2010). Vendo Vozes: uma viagem ao mundo dos surdos. São Paulo: Companhia das Letras.

Yin, R. K. (2010). Estudo de Caso: planejamento e métodos. Porto Alegre: Bookman.

\section{Endereço para correspondência \\ Amanda Galerani Thomaz}

Universidade Federal do Paraná - UFPR

Departamento de Psicologia

Praça Santos Andrade, $2^{\circ}$ andar, CEP 80020-300, Curitiba - PR, Brasil

Endereço eletrônico: amandagthomaz@gmail.com

Joanneliese de Lucas Freitas

Universidade Federal do Paraná - UFPR

Departamento de Psicologia

Praça Santos Andrade, $2^{\circ}$ andar, CEP 80020-300, Curitiba - PR, Brasil

Endereço eletrônico: joanneliese@gmail.com

Recebido em: 06/01/2015

Reformulado em: 04/07/2016

Aceito em: 04/07/2016 


\section{Notas}

* Psicóloga graduada pela Universidade Federal do Paraná. Atualmente residente do Programa de Saúde da Família da Prefeitura de Curitiba.

** Doutora em Psicologia pela Universidade de Brasília. Professora do Departamento de Psicologia da Universidade Federal do Paraná.

${ }^{1}$ Inserção nossa. 